Research Paper

\title{
Characterization of a thermostable endoglucanase produced by Isoptericola variabilis sp. IDAH9
}

\author{
Maryam Azizi ${ }^{1,2}$, Jafar Hemmat ${ }^{1}$, Seyed Morteza Seifati², \\ Ibrahim Torktaz ${ }^{1}$, Soodabeh Karimi ${ }^{1}$
}

1Biotechnology Department, Iranian Research Organization for Science and Technology, Tehran, Iran. 2Department of Biology, Ashkezar Branch, Islamic Azad University, Ashkezar, Iran.

Submitted: October 31, 2014; Approved: March 21, 2015.

\begin{abstract}
This study aimed to isolate and evaluate the cellulase activity of cellulolytic bacteria in hot springs of Dehloran, Ilam province, Iran. Water and sludge samples were collected from the hot springs and the bacterial enrichment was performed in a medium containing rice barn and carboxymethyl cellulose $(\mathrm{CMC})$. The cultures were incubated at $50{ }^{\circ} \mathrm{C}$ in aerobic conditions. The bacteria were isolated on $\mathrm{CMC}$ agar (1\%) medium. Cellulase assay of the isolates was measured by the evaluation of endoglucanase enzyme activity, which is also called as carboxymethyl cellulase (CMCase). The isolated thermotolerant bacteria were then identified and optimized for the production of CMCase. Moreover, stabilizing elements of the enzyme were identified with in silico approach. The chosen isolate was identified as Isoptericola variabilis sp. IDAH9. The identified strain produced the most thermostable CMCase at a concentration of $5.6 \mathrm{~g} / \mathrm{L}$ of ammonium sulfate, $9 \mathrm{~g} / \mathrm{L}$ CMCase or $12 \mathrm{~g} / \mathrm{L}$ rice bran, $0 / 6 \%$ Tween- 80 , and $0.2 \%$ sucrose. The produced enzyme showed $80 \%$ of the residual activity after $1 \mathrm{~h}$ of incubation at $65^{\circ} \mathrm{C}$. In silico data indicated that the remaining residual activity was due to the redundant stabilizing elements in the protein structure. Consequently, I. variabilis can be isolated from the extreme environment and has a thermostable endoglucanase which may be used for various applications after studying them.
\end{abstract}

Key words: carboxymethyl cellulase, endoglucanase, thermophiles, protein structure.

\section{Introduction}

Cellulose is one of the main structural components of lignocellulosic wastes and the most renewable biomaterial that has been chosen as a carbon source by a wide range of cellulolytic microorganisms including fungi and bacteria. The degradation of cellulose is accomplished by the cooperative action of three types of enzymes: beta-1,4-endoglucanase (also called as carboxymethyl cellulase (CMCase), EC 3.2.1.4), beta-1,4-glucan cellobiohydrolases (CBH, filter paperase (FPase), EC 3.2.1.91), and beta-glucosidases (cellobiase, EC 3.2.1.21). CMCase and FPase act synergistically on cellulose to produce small oligosaccharides and cellobiose that are then cleaved by betaglucosidases to glucose, which can be used by the microor- ganisms (Acosta-Rodriguez et al., 2005; Kuhad et al., 2011; Picart et al., 2008).

Cellulases have several applications (Sukumaran et al., 2005; Van Maris et al., 2006); however, thermostability is one of the most important criteria for its application in the industries (Bredholt et al., 1995; Ferrer et al., 2007; Bhalla et al., 2013; Karnaouri et al., 2014). For example, one major bottleneck in front of the development of lignocellulosic biofuel industry is the unfeasibility of hydrolysis phase of cellulose. The biorefining process remains economically unachievable due to the lack of biocatalysts that can overcome costly problems such as cooling from high temperature, pumping of oxygen/stirring, and neutralization from acidic or basic $\mathrm{pH}$ (Dashtban et al., 2010). Mining enzymes from extreme environments is an alternative solution for

Send correspondence to J. Hemmat. Biotechnology Department, Iranian Research Organization for Science and Technology, P.O. Box: 14155-6343, Tehran, Iran. E-mail: j.hemmat@gmail.com. 
these problems. Consequently, isolation of microorganisms such as extremophiles from these habitats and characterization of their biocatalysts is the interest of many researchers (Bergquist et al., 1999; Bredholt et al., 1995; Ferrer et al., 2007). Moreover, these kinds of biocatalysts are noticeable and confident templates for protein engineering purposes. There are several reports regarding isolation of thermophilic bacteria and fungi and the characterization of their endoglucanase activity (Bhalla et al., 2013; Hreggvidsson et al., 1996; Karnaouri et al., 2014; Mead et al., 2012; Susanti et al., 2012). The importance of thermophilic bacteria and their thermostable enzymes to overcome the bottlenecks of existing processes of lignocellulosic biomass conversion, the effect of high temperatures on bioprocessing of saccharification and fermentation, and the new trends in improved lignocellulosic conversion to bioethanol have also been discussed (Bhalla et al., 2013; Li D-C et al., 2011).

The hot springs are extreme environments that host extremophiles. There are several reports on isolation of thermostable microorganisms including thermophilic cellulolytic anaerobes, thermophilic fungi, thermophilic anaerobic cellulolytic bacterium, Fervidobacterium riparium sp. nov., and alkaline thermophilic fungi, Aneurinibacillus thermoaerophilus wbs2, from hot springs (Acharya and Chaudhary, 2012; Bredholt et al., 1995; Li et al., 2011; Podosokorskaya et al., 2011). This study purposed to isolate cellulolytic and thermotolerant bacteria from hot springs of Dehloran, Ilam province in South-West of Iran. The selected isolated bacterium was then identified as Isoptericola variabilis sp. IDH9 and optimized the CMCase production from this source. Also, stabilizing elements for CMCase were identified through in silico approach by predicting the structure of endoglucanase isolated from $I$. variabilis. Subsequently, the entire protein structure of endoglucanse was scanned concerning the stabilizing regions.

\section{Materials and Methods}

\section{Isolation of thermophilic cellulase-producing bacteria}

The water and soil samples were collected from hot springs of Dehloran (32 $41{ }^{\prime} 39^{\prime \prime} \mathrm{N}$ and $\left.47^{\circ} 16^{\prime} 04^{\prime \prime} \mathrm{E}\right)$ in the Ilam province of South-West of Iran. Then, $1 \mathrm{~g}$ of wet soil was added to $70 \mathrm{~mL}$ of two different mediums which have been previously described and supplemented with rice bran or carboxymethyl cellulose (CMC) as the sole source of carbon $(1 \% \mathrm{w} / \mathrm{v})$ in $250 \mathrm{~mL}$ flasks (Crawford and McCoy, 1972; Rastogi et al., 2010). The $\mathrm{pH}$ of the medium was adjusted to 7.0. The flasks were kept in a shaking incubator at $50{ }^{\circ} \mathrm{C}$ and $150 \mathrm{rpm}$ for 1 week. At the end of the week, the culture medium was transferred to the fresh medium ( $2 \%$ $\mathrm{v} / \mathrm{v}$ ) and the process was run as described before. After 6 weeks, samples of the culture were used to prepare the serial dilutions (using sterile saline water $0.9 \% \mathrm{NaCl}$ ). Each dilution was spread on a plate containing enrichment medium and $\mathrm{CMC}$ agar (both at $1 \% \mathrm{w} / \mathrm{v}$ ) to isolate thermophilic cellulose-degrading bacteria. The single colonies that appeared after incubation at $50{ }^{\circ} \mathrm{C}$ were isolated and named (D2, D3, D5, and D9) for further study.

\section{Endoglucanase activity assay}

Endoglucanase activity of D2, D3, D5, and D9 isolates was primarily screened with Congo red plate (Teather and Wood, 1982) and also with 3,5-dinitrosalicylic acid (DNS) method. First, the CMCase activity was evaluated on Congo red plates containing enriched medium as well as $0.1 \% \mathrm{CMC}$ and $0.8 \%$ agar. The supernatant of the enzyme solution $(20 \mu \mathrm{L})$ of the isolates was poured on the plate. After 30 min incubation at $37{ }^{\circ} \mathrm{C}$, the medium was flooded with an aqueous solution of Congo red (0.1\%) for $15 \mathrm{~min}$. The Congo red solution was then poured off, and plate was further treated by flooding with $1 \mathrm{M} \mathrm{NaCl}$ for $15 \mathrm{~min}$. Enzyme activity was observed in the halo of discoloration. An industrial cellulase enzyme was used as a positive control and compared with samples' halo. All tests were done in triplicates and the bars represent standard deviation (SD).

The DNS method is based on the determination of the amount of liberated sugars from CMC \%1 substrate as described before with some modifications (Assareh et al., 2012). The enzyme assay mixture $(2 \mathrm{~mL})$ contained $1 \mathrm{~mL}$ of supernatant of enzyme solution and $1 \mathrm{~mL}$ of $1 \%(\mathrm{w} / \mathrm{v})$ $\mathrm{CMC}$ solubilized in $50 \mathrm{mM}$ phosphate buffer ( $\mathrm{pH} 7$ ). The reaction was conducted by the incubation of the mixture at $50{ }^{\circ} \mathrm{C}$ for $30 \mathrm{~min}$. The reaction was then stopped by the addition of DNS solution $(2 \mathrm{~mL})$. The treated sample was boiled for $10 \mathrm{~min}$ and then sodium-potassium tartarate $(1 \mathrm{~mL})$ was added and cooled by the addition of $5 \mathrm{~mL}$ water for color stabilization. The absorbance of the developed color was measured at $540 \mathrm{~nm}$ and converted to the concentration of reducing sugars using a standard curve created by various concentrations of glucose (Merck) as standard. One unit of the enzyme activity is defined as the amount of enzyme that releases $1 \mathrm{mM}$ of reducing sugars per $30 \mathrm{~min}$.

\section{Evaluation of enzyme production and growth}

The growth pattern and endoglucanase production of the selected four isolates were investigated by using a medium which have been described before (Liang et al., 2009) by interval sampling during 10 days. The growth was examined by measuring the optical density in $540 \mathrm{~nm}$. The supernatant of the samples was stored in $-20^{\circ} \mathrm{C}$ to be used for endoglucanase activity assay. 


\section{Identification of the bacterial isolate}

The four isolates were subjected to standard biochemical tests (Bergey's manual) and 16S rRNA gene sequencing. The isolation of genomic DNA was carried out according to Fermentase genomic DNA purification kit. The extracted DNA was used as the template for PCR amplification of 16S rRNA gene using universal primers: F(5'-CCGAATTCGTCGACAACAGAGTTTGATCCTGG CTCAG-3') and R- (5'-CCCGGGATCCAAGCTTACGG TTACCTTGTTACGACTT-3'). The reaction mixture $(30 \mu \mathrm{L})$ contained: each primer at a concentration of $0.75 \mu \mathrm{L}$, Master Mix PCR (2X) at a concentration of $15 \mu \mathrm{L}$, template DNA $(1.5 \mu \mathrm{L})$, and $\mathrm{ddH}_{2} \mathrm{O}(12 \mu \mathrm{L})$. The following thermal profile was used for the PCR: $94{ }^{\circ} \mathrm{C}, 1.5 \mathrm{~min}$; 35 cycles of $94{ }^{\circ} \mathrm{C}, 45 \mathrm{~s} ; 65^{\circ} \mathrm{C}, 60 \mathrm{~s} ; 72{ }^{\circ} \mathrm{C}, 90 \mathrm{~s} ; 1$ cycle of $72{ }^{\circ} \mathrm{C}, 10 \mathrm{~min}$. The PCR product was purified using the quick PCR purification kit (Fermentase) and sequenced by Bionear Company, Korea. The $16 \mathrm{~S}$ rDNA sequence of the isolates were submitted to GenBank. The similarity search for the sequence was carried out using the BLAST program. Phylogenetic tree was constructed by the neighborhood-joining method using MEGA 6 software (Tamura et al., 2007). Bootstrap resampling analysis for 1,000 replicates was performed in order to estimate the confidence of the tree topologies.

\section{Optimization of medium culture for improving enzyme production}

\section{The effect of inducer on enzyme production}

In order to study the effect of inducer on the cellulase production of the selected isolate, sucrose at the concentrations of 0.1 and $0.2 \%(\mathrm{w} / \mathrm{v})$ was added to the culture medium containing $1 \% \mathrm{CMC}$ as the carbon source. The control medium contained no sucrose. In the same condition, endoglucanase activity was compared at the end of each week.

\section{The effect of Tween-80 on enzyme production}

Among the surfactants, Tween- 80 was added to the culture medium at concentrations of $0.1,0.2,0.4$, and $0.6 \%$ $(\mathrm{v} / \mathrm{v})$ and its effect on the endoglucanase production was investigated.

\section{The effect of carbon source on enzyme production}

In order to study the effect of carbon source on endoglucanase production, same flasks of medium were prepared from the basic culture medium in a manner that each flask contained $1.5,3,6,9$, and $12 \mathrm{~g} / \mathrm{L}$ of CMC or rice bran as the carbon source. At the end of the experiment, the endoglucanase activity of the supernatants was measured.

\section{The effect of nitrogen source on enzyme production}

In order to assay the effect of nitrogen source on enzyme production, different concentrations of ammonium sulfate by $1.4,2.8,5.6,8.4,11.2$, and $16.8 \mathrm{~g} / \mathrm{L}$ was used as the sole nitrogen source. Then, the endoglucanase activity of supernatant was measured.

\section{Evaluation of thermal stability}

In order to measure the thermal stability of endoglucanase, the supernatant of the culture medium was placed in a water bath at 50 and $55^{\circ} \mathrm{C}$ and sampling was done at intervals of $0.5,1,2$, and $4 \mathrm{~h}$ from the solution. The residual activity of endoglucanase was measured after test times. The control of experiment was the same sample before placing in the water bath.

\section{Protein structure prediction}

As in silico approach, we tried to predict threedimensional (3D) structure of $I$. variabilis endoglucanase (accession number: 334338181). To do this, a combination of domain recognition and Hidden Markov Model (HMM) following a rigid body assembly by Modeller V 9.12 software were performed. Because the most identical crystallography template to I. variabilis cellulase had low similarity, we used ps 2 protein modeling server (Chen et al., 2006) to predict 3D structure based on similar domains, and by this way, the number of misaligned residues were decreased. Also, for finding a rational template for misaligned parts of query sequence, Sequence Alignment and Modeling (SAM) -T08, a HMM-based protein prediction webserver (http://compbio.soe.ucsc.edu/SAM_T08/T08query.html) was used. In this method, first a cluster of HMM made by querying similar sequences and alignment was performed between a HMM database of structures and the constructed HMM cluster of query. SAM algorithm made the final complete model of the query. Finally, the retrieved models from domain recognition and HMM methods were used as the template for Modeller v 9.12 (https://salilab.org/modeller/release.html). The final complete model was predicted and optimized and then energy minimization was performed on predicted model. This model was used for further analysis.

\section{Statistical analysis}

All experiments were replicated at least three times. Statistical analyses were performed by paired test, one-way ANOVA, and data were expressed as the averages \pm SD. The error bars were calculated using the averages and SD of the means by Microsoft excel 2007. Differences were considered to be statistically significant when $p$ value $p<0.05$, $\mathrm{p}<0.01$, and $\mathrm{p}<0.001$. 


\section{Results and Discussion}

\section{Isolation and identification of thermophilic cellulose-utilizing bacteria}

Among the isolated colonies from hot springs of Dehloran, four of the isolates, named D2, D3, D5, and D9, indicated the ability to create a clear halo of cellulase activity on Congo red plates during incubation and therefore displayed higher cellulase activity. During the quantitative tests, it was determined that the endoglucanase activity of D9 was higher than others (Figure 1). In addition, D9 isolate was able to use not only microcrystal cellulose but also rice bran and commercial CMC as a carbon source. Therefore, D9 was selected for further studies. The partial $16 \mathrm{~S}$ rDNA sequence of D9 isolate was obtained and submitted to GenBank. The Accession number for Isoptericola sp. IDAH9 is KM279624. According to molecular and physiological characteristics, the D9 isolate was determined as $I$. variabilis strain (IDAH9). Phylogenetic analysis using Mega 6 software revealed that the strain IDAH9 formed a clad with $I$. variabilis supported by 100 bootstrap values (Figure 2). The degree of sequence similarity of strain T1 to I. variabilis was $99 \%$.

I. variabilis sp. Nov first reported as Cellulomonas variformis and a cellulolytic bacterium from the hindgut of the termite Mastotermes darwiniensis (Bakalidou, 2002). It was reclassified as I. variabilis (Stackebrandt, 2004). Indeed, Cellulomonas species are cellulolytic bacteria that have been isolated from different sources containing cellulose materials. Cellulomonas sp. sw97 has been isolated

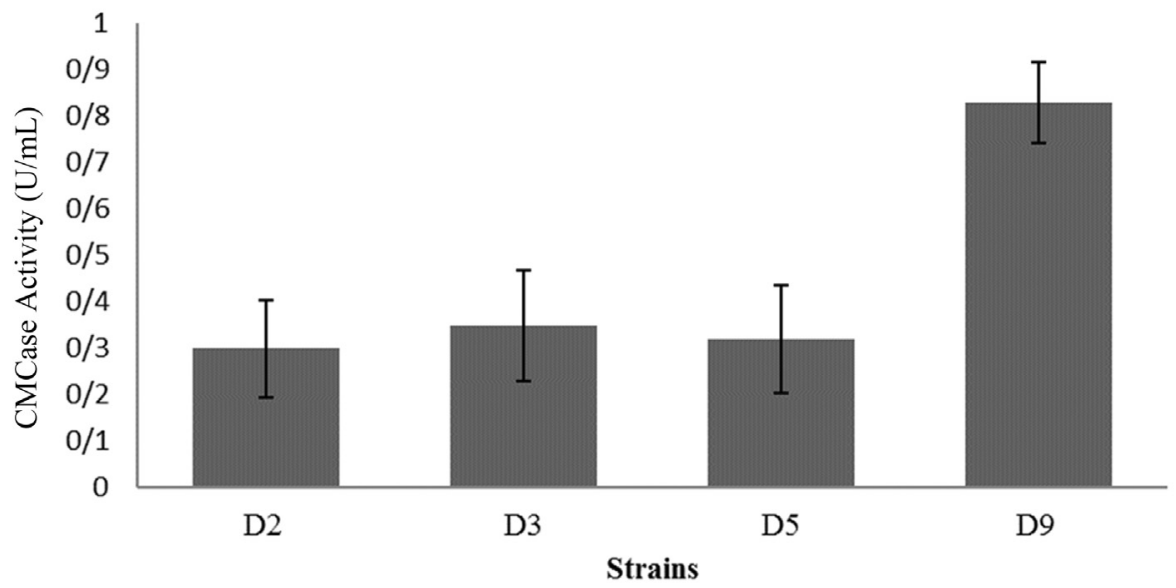

Figure 1 - Endoglucanase (CMCase) activity of isolated cellulase-producing bacteria. The cellulase-producing bacterial strains were compared according to CMCase activity $\left(\mathrm{p}^{*}<0.01\right)$.

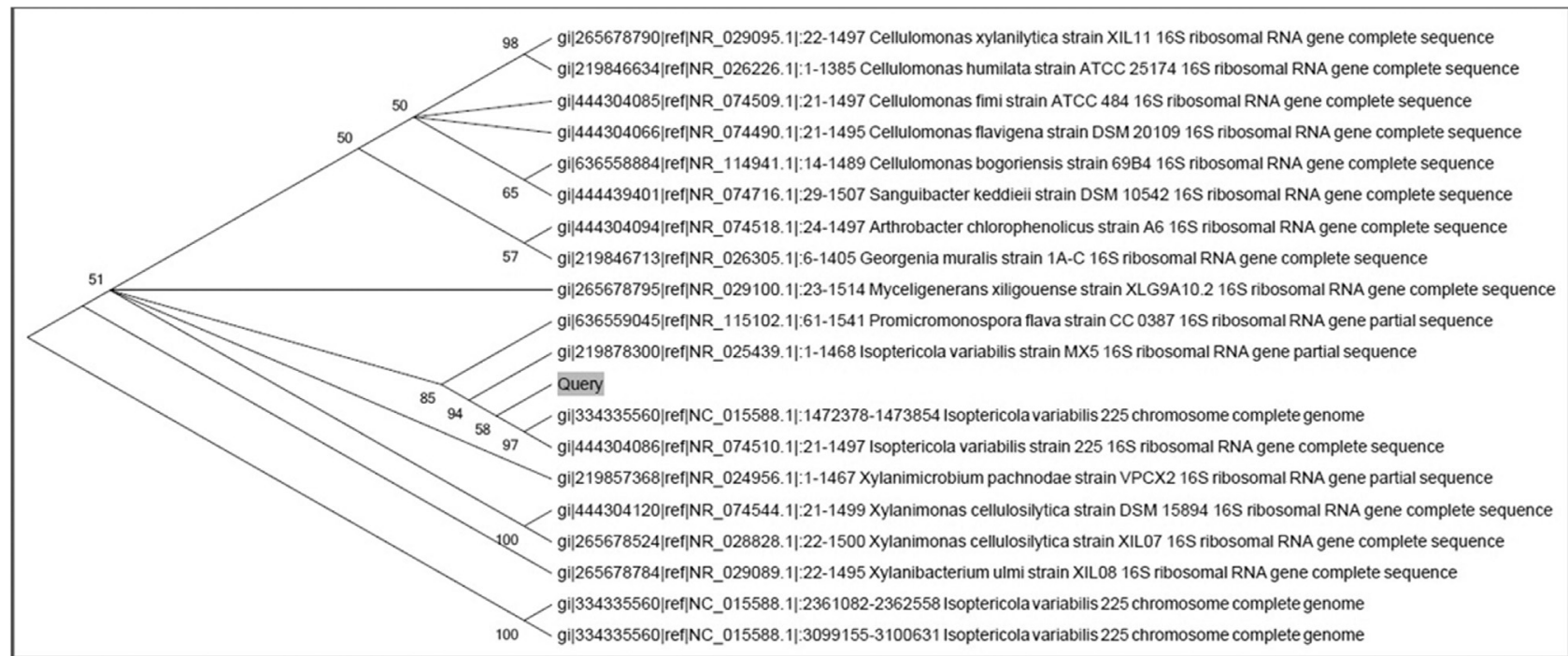

Figure 2 - Phylogenetic tree showing the relationship between 16S rDNA sequence of Isoptricola variabilis strain (IDAH9) which was isolated in this study and the most related sequences in GenBank. The tree was constructed by MEGA 6 using neighbor-joining algorithm with 1000 bootstrapping. The scale bar represents 0.005 substitutions per amino acid position. Numbers at the node are the bootstrap values (\%). 
from silkworm-gut and characterized its exoglucanase and endoglucanase activity (Hemmat, 2001). Interestingly, we isolated another Isoptericola sp. from a hot spring located in north of Iran (data not shown). I. variabilis has been reported as one of five amylolytic bacterial strains from Sao Paulo Zoo composting unit, which showed strong induction in response to the combination of $1 \%$ starch at $39{ }^{\circ} \mathrm{C}$ (Pascon et al., 2011). Although, Isoptericola halotolerans sp. has been isolated from saline soil (Zhang et al., 2005) but the species has not been reported from hot springs suggesting that this is a novel information.

\section{Evaluation of growth and endoglucanase production} of $I$. variabilis sp. IDAH9

Evaluation of the growth and endoglucanase production over time indicated that the I. variabilis sp. IDAH9 has $0.64 \mathrm{U} / \mathrm{mL}$ of endoglucanase activity at the end of logarithmic phase of growth. Then the enzyme production was continued during death phase (Figure 3).

\section{Optimization of enzyme production in IDAH9 strain}

After selecting the appropriate strains, the conditions for enzyme production were optimized. To do this, the effect of rice bran and CMC, ammonium sulfate, Tween- 80 , and sucrose were evaluated.

\section{The effect of different amount of carbon sources for enzyme production}

The results indicated that commercial $\mathrm{CMC}$ was more favorable carbon source than rice bran for the production endoglucanase $\left(\mathrm{p}^{*}<0.01\right)$. It is suggested that this is due to the less complexity and hence easy hydrolysis of CMC by the isolated strain (Wood and Bhat, 1988). Moreover, $9 \mathrm{~g} / \mathrm{L}$ was the best concentration of CMC for the enzyme production (Figure 4). Also, the same result was detected during

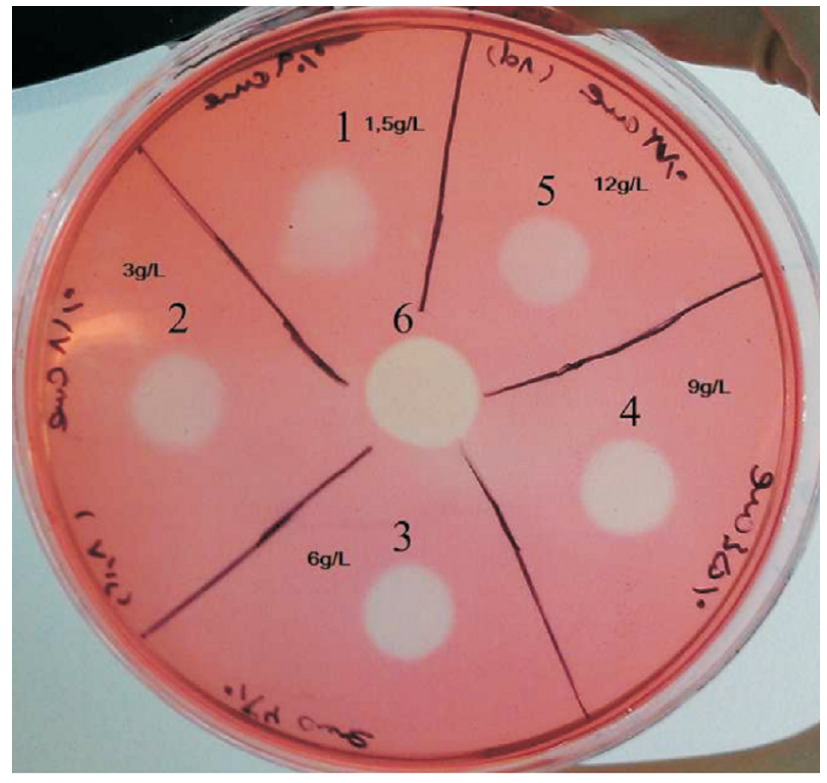

Figure 4 - Endoglucanase (CMCase) production by Isoptericola variabilis sp. DAH9 with different densities of carboxymethyl cellulose (CMC) after 8 days of incubation. 1-5: Mendel medium containing 1.5, 3, 6, 9, and 12 $\mathrm{g} / \mathrm{L} \mathrm{CMC}$, respectively and 6: positive control.

the quantitative measurement, and $1 / 1 \pm 0.09 \mathrm{U} / \mathrm{mL}$ endoglucanase activity was achieved when the CMC concentration was $9 \mathrm{~g} / \mathrm{L}$ (Figure 5) ( $\left.\mathrm{p}^{*}<0.01\right)$. Similarly, $\mathrm{CMC}$ was found optimum for cellulase production of thermotolerant CMCase from Bacillus sp. isolated from cow dung (Sadhu et al., 2013). Although the increasing of $\mathrm{CMC}$ concentration over $9 \mathrm{~g} / \mathrm{L}$ decreased CMCase production, increasing the rice bran to $12 \mathrm{~g} / \mathrm{L}$ increased the enzyme production (Figures 5, 6). This result can be described by the lower percent of carbon composition of rice bran (about $40 \%$ of total weight). Accordingly, CMCase production was found to be dependent upon the nature of the carbon source used in the culture media.

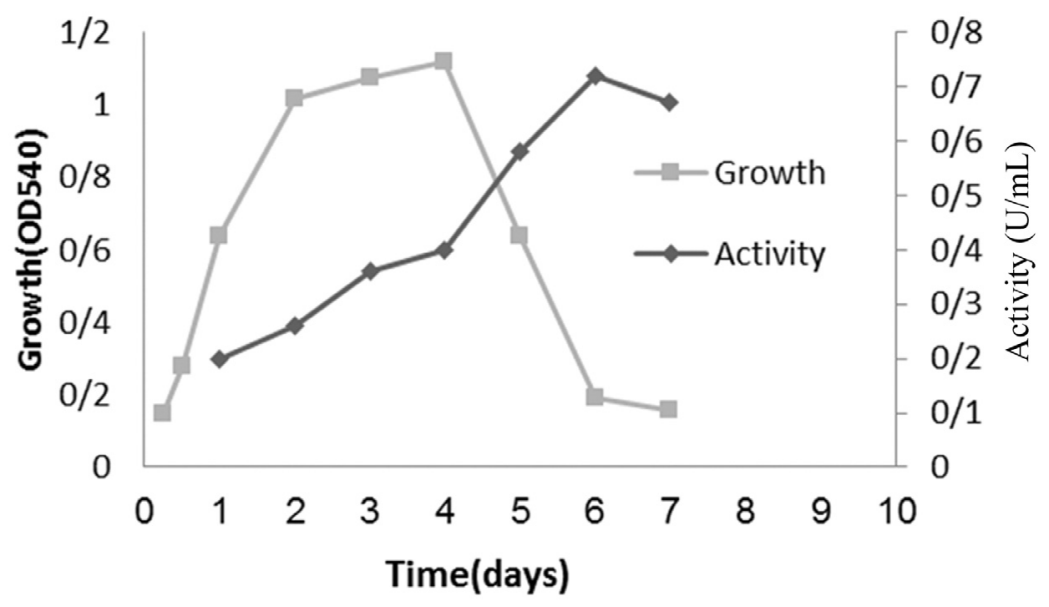

Figure 3 - Evaluation of growth curves of Isoptericola variabilis sp. IDAH9 and the relation of endoglucanase production over time (p*<0.05). 


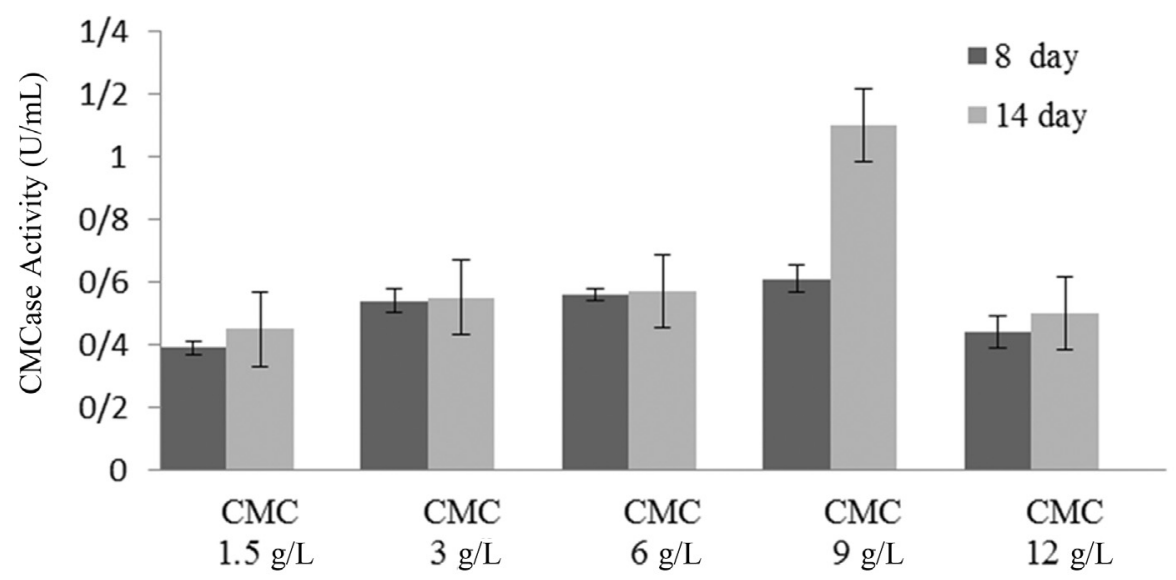

Figure 5 - The effect of different concentrations (1.5- $12 \mathrm{~g} / \mathrm{L})$ of CMC on CMCase production during 8 and 14 days $\left(\mathrm{p}^{*}<0.02\right)$.

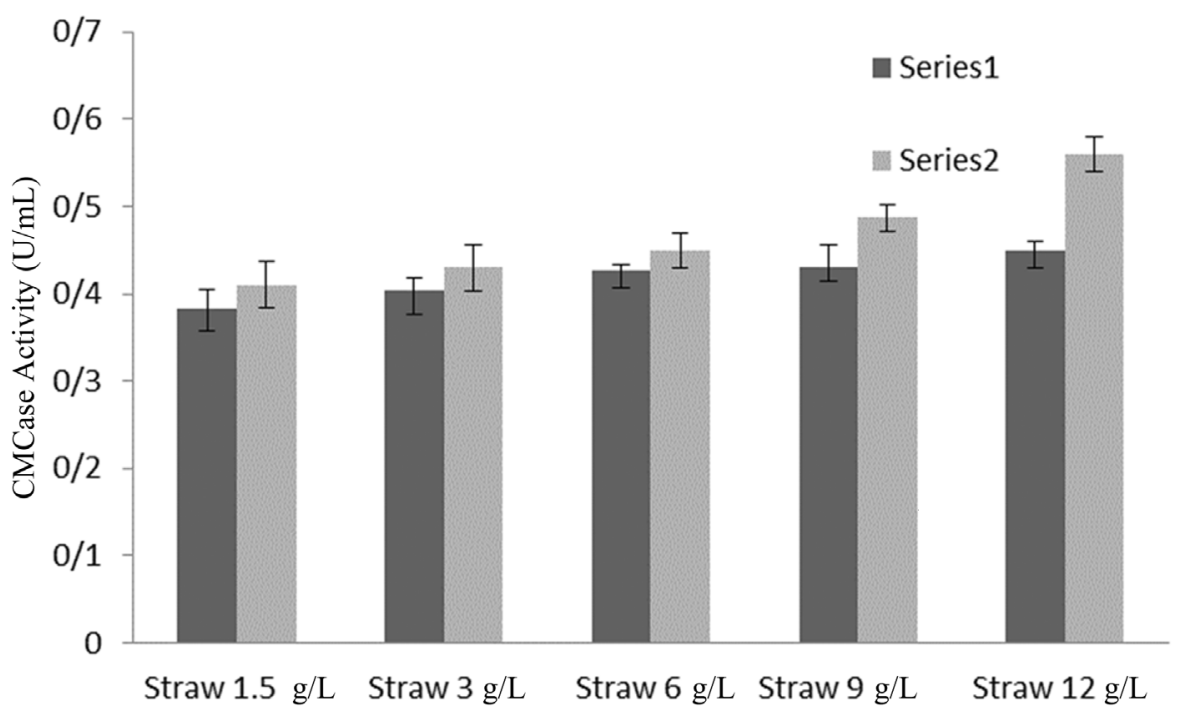

Figure 6 - The effect of different concentration $(1.5-12 \mathrm{~g} / \mathrm{L})$ of rice bran on CMCase production during 8 and 14 days $\left(\mathrm{p}^{*}<0.01\right)$.

The effect of different concentrations of nitrogen source on enzyme production

As it is shown in Figure 7, the I. variabilis sp. IDAH9 has produced the greatest amount of CMCase at a concentration of $5.6 \mathrm{~g} / \mathrm{L}$ of ammonium sulfate at the 8th and 14th days. There are no significant difference $(p=0.412)$ between the results of two periods; however, ammonium sulfate $(5 / 6 \mathrm{~g} / \mathrm{L})$ has shown significant differences during both periods ( $p=0.004, p=002$, respectively). It was also observed that higher concentrations of ammonium sulfate had negative effect on the CMCase production and it was accelerated during passage of time.

The effect of different concentrations of sucrose on enzyme production

The results showed that while the isolate produced $0.29 \pm 0.01 \mathrm{U} / \mathrm{L}$ and $0.32 \pm 0.05 \mathrm{U} / \mathrm{mL}$ of endoglucanase in the absence of glucose on the 8th and the 14th day, respectively, the amount of enzyme was increased in presence of sucrose (Figure 8). Also, the results showed that the enzyme production was greater on the 14th day than the 8th day ( $\left.\mathrm{p}^{*}<0.01\right)$. Some materials, including some of the sugars, in the presence of cellulose can induce the production of cellulase. Cellobiose induced cellulolytic activity in Cellulomonas sp. IIBC (Rodriguez, 1996). When glucose or cellobiose was used with cellulose in a thermophilic Brevibacillus sp., cellulase activities were enhanced 10 times (Liang et al., 2009).

\section{The effect of different concentrations of Tween-80 on enzyme production}

The effect of Tween- $80 \% 0 / 1, \% 0 / 2, \% 0 / 4$, and $\% 0 / 6$ on the endoglucanase enzyme production was evaluated where the amount of CMC was $3 \mathrm{~g} / \mathrm{L}$. The results indicated 


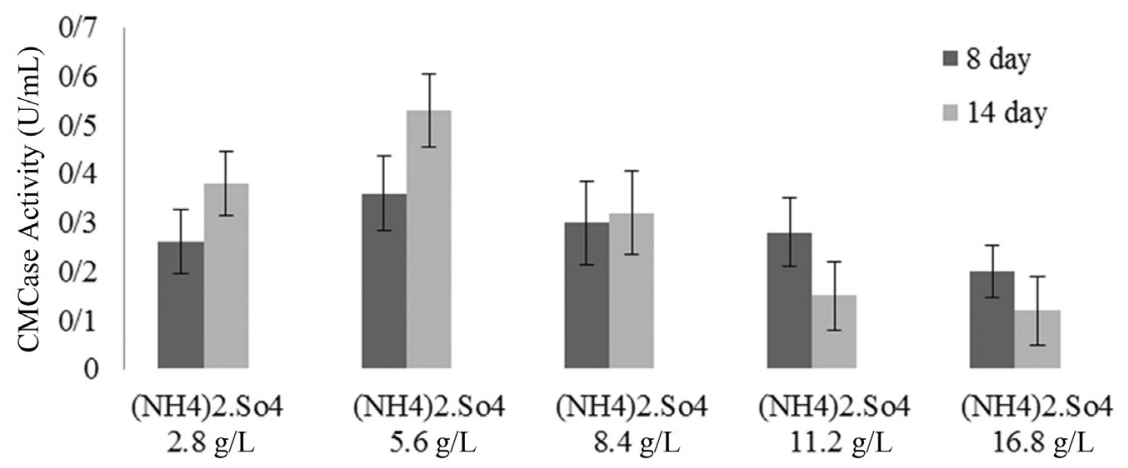

Figure 7 - The effect of nitrogen source on CMCase production.

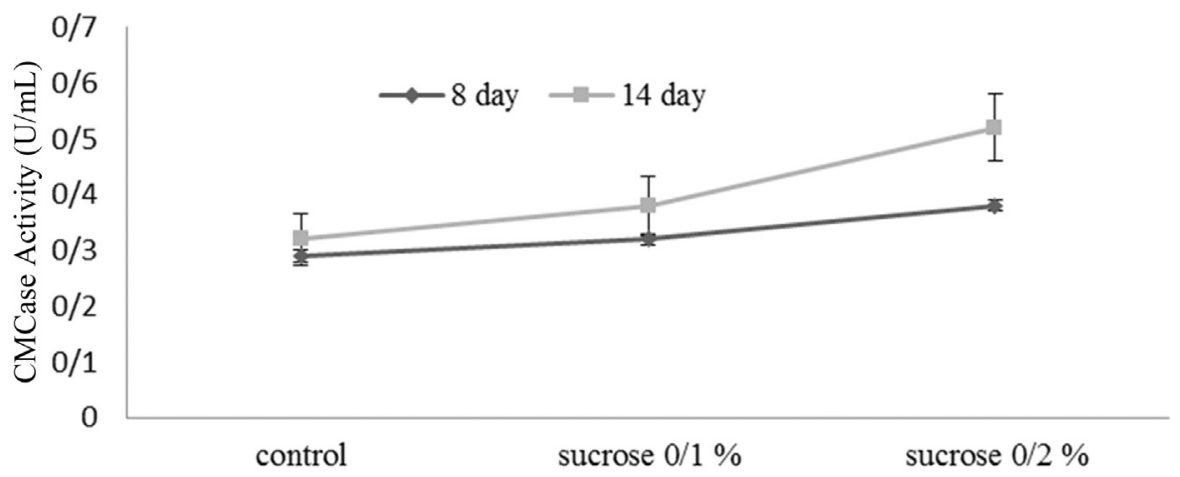

Figure 8 - The effect of inducer on endoglucanase (CMCase) production. Control: medium without sucrose $\left(\mathrm{p}^{*}<0.01\right)$.

that increasing Tween-80 concentration increased the CMCase activity in supernatant till 8 days, and then the activity has been decreased in all concentration of Tween- 80 . As well as a concentration of $\% 0 / 6$ has best effect on enzyme activity of the supernatant $\left(\mathrm{p}^{*}<0.01\right)$ (Figure 9). It has been reported that Tween- 80 increases the rate of phytase production in Aspergillus ficuum (Liang et al., 2009), xylanase production by Aspergillus flavus DFR (Pal and Khanum, 2011), CMCase production by Geobacilus (Assareh et al., 2012) and Cellulomonas flavigena (Sami et al., 1988). It is believed hat surfactants facilitates the release of enzymes by decreasing the phospholipid content of the cell membrane and thereby increasing its porosity.

\section{Valuation of thermal stability}

Residual activities of endoglucanase of $I$. variabilis sp. DAH9 were $94,91.5,82$, and $71 \pm 3.0 \%$, after $0.5,1,2$, and $4 \mathrm{~h}$ incubation at $55^{\circ} \mathrm{C}$, respectively. Although, activity of this enzyme gradually declined with the increase of temperature from 55 to $65{ }^{\circ} \mathrm{C}$ (Figure 10), the thermal sta-

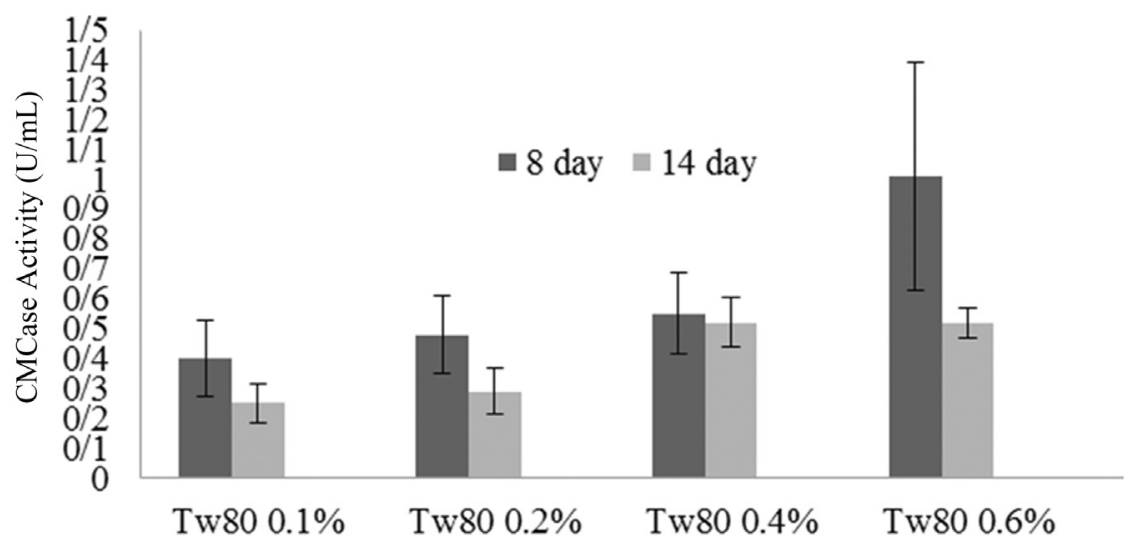

Figure 9 - The effect of Tween -80 on CMCase production $\left(\mathrm{p}^{*}<0.01\right)$. 


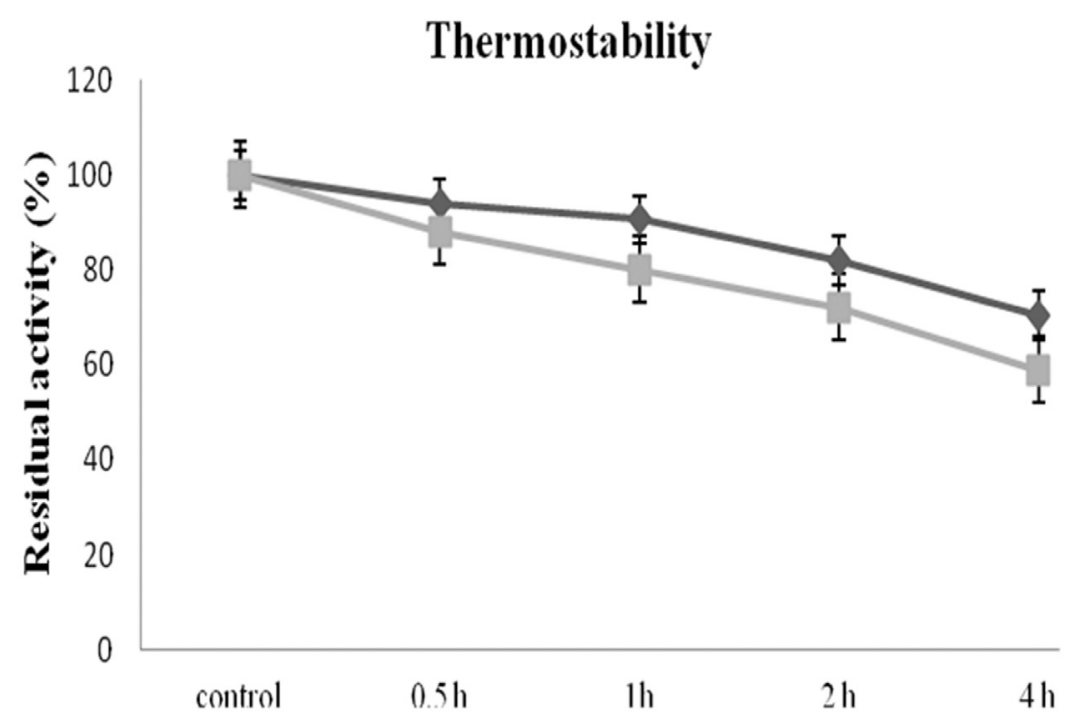

Figure 10 - Evaluation of thermal stability of endoglucanase activity of selected isolates in 55 and $65^{\circ} \mathrm{C}\left(\mathrm{p}^{*}<0.01\right)$.

bility of the enzyme was noticeable and sufficient activity of the enzyme ( $88,80,72$, and $59 \%$, respectively) was present. However, the CMCase of mesophilic Cellulomonas flavigena lost its activity when it was incubated at $70{ }^{\circ} \mathrm{C}$ for 30 min (Sami et al., 1988).

\section{Determination of stabilizing regions in protein structure}

For the determination of stabilizing regions, the predicted structure (Figure 11) was further analyzed by SCide web-based algorithm (Dosztanyi et al., 2003). The results of the analysis are depicted in Figure 12. This indicates that the stabilizing residues are mainly localized at 200 to 260 and 300 to 350 . Also, there are stabilizing regions at $\mathrm{C}$ terminal of the protein.

\section{Conclusion}

It may be concluded that the studied hot springs have noticeable biodiversity of thermophilic and cellulolytic bacteria which can be cultured and isolated. Among the isolates, I. variabilis sp. DAH9 could produce noticeable thermostable endoglucanase by using low-priced carbon sources such as rice barn and commercial CMC. Therefore, it has the potential to produce thermostable endoglucanase which could have application for cellulose hydrolyzing industries. In silico study of the most related endoglucanase revealed that this protein contains several stabilizing centers which made it a thermostable enzyme. Thermotolerant bacteria which produce thermostable enzymes have some comparative advantages to thermophiles faced with some limitations in scaling up. Further in-depth investigation is

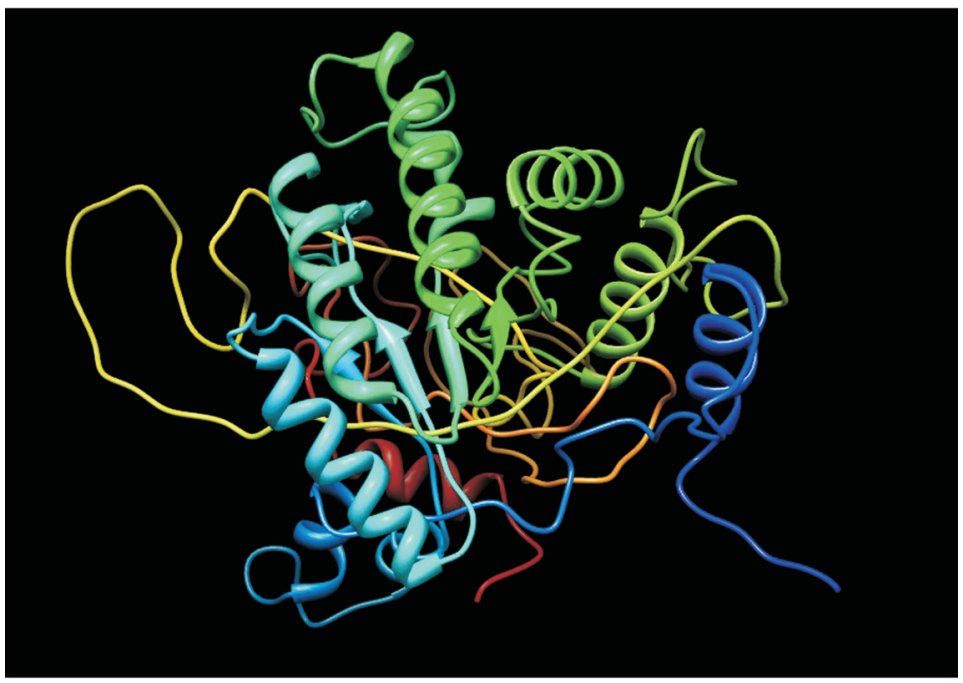

Figure 11 - The predicted structure of Isoptericola variabilis cellulase. 


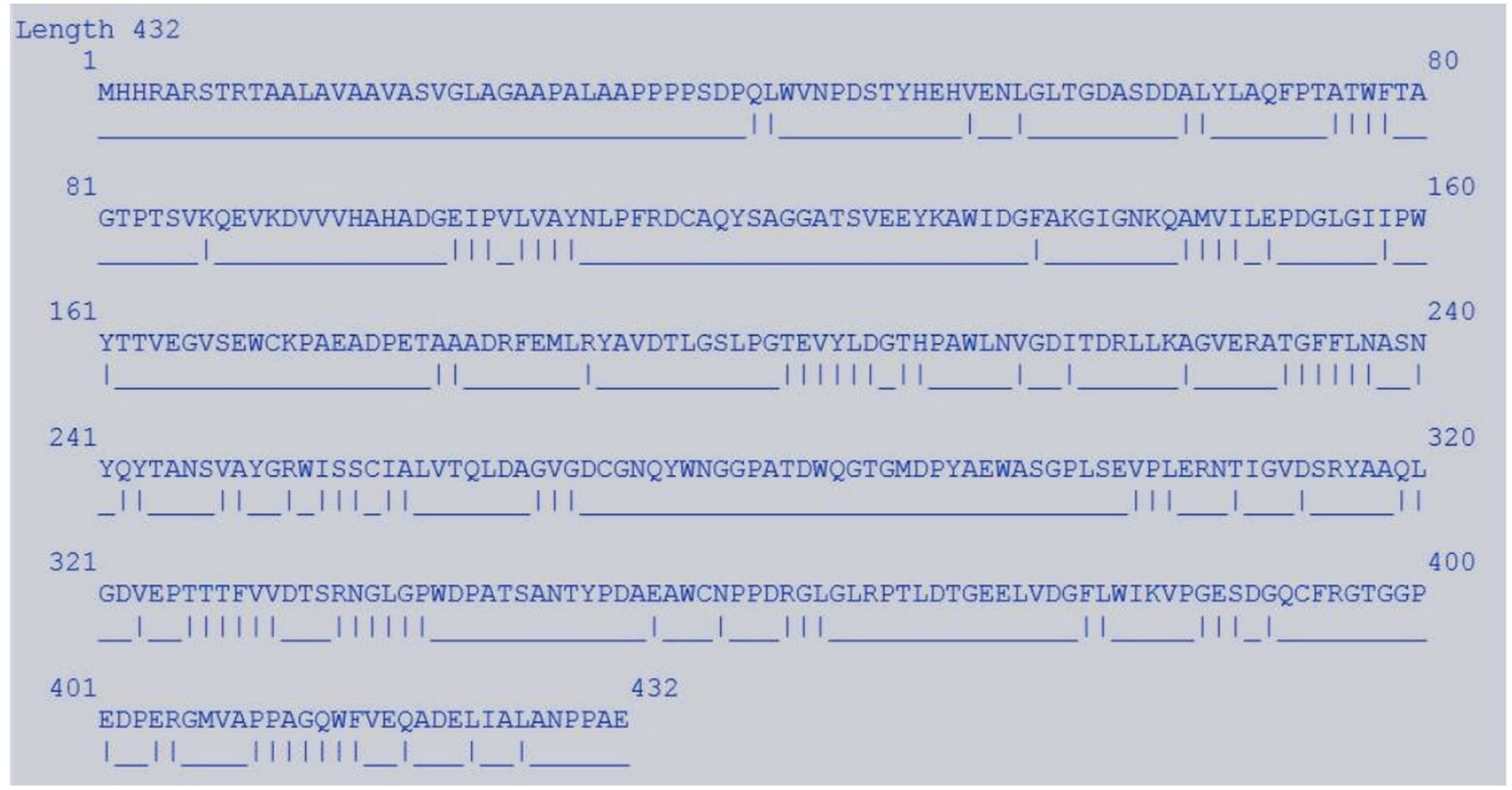

Figure 12 - Location of stabilization center elements in the sequence are marked with " ", while other 6 positions are marked with " _".

needed on optimization of cost-effective substrate for bulk production of enzymes and molecular basis of thermostability. Also, the identified stabilizing centers of the enzyme has the potential for application in protein engineering purposes to reach a more thermostable enzyme with even more turn over and specific activity.

\section{Acknowledgments}

The authors would like to appreciate the Biotechnology Department of Iranian Research Organization for Science and Technology (IROST), Tehran, Iran. This work was partially funded by the Iran National Science Foundation (INSF) with the grant number of 87041530 .

\section{References}

Acharya S, Chaudhary A (2012) Alkaline cellulase produced by a newly isolated thermophilic Aneurinibacillus thermoaerophilus WBS2 from hot spring, India. Afr J Microbiol Res 6:5453-5458.

Acosta-Rodriguez I, Pinon-Escobedo C, Zavala-Paramo MG et al. (2005) Degradation of cellulose by the bean-pathogenic fungus Colletotrichum lindemuthianum. Production of extracellular cellulolytic enzymes by cellulose induction. Antonie Van Leeuwenhoek 87:301-310.

Assareh R, Shahbani Zahiri H, Akbari Noghabi K et al. (2012) Characterization of the newly isolated Geobacillus sp. T1, the efficient cellulase-producer on untreated barley and wheat straws. Bioresour Technol 120:99-105.

Bhalla A, Bansal N, Kumar S et al. (2013) Improved lignocellulose conversion to biofuels with thermophilic bacteria and thermostable enzymes. Bioresour Technol 128:751759.

Bergquist PL, Gibbs MD, Morris DD et al. (1999) Molecular diversity of thermophilic cellulolytic and hemicellulolytic bacteria. FEMS Microbiol Ecol 28:99-110.

Bredholt S, Mathrani IM, Ahring BK (1995) Extremely thermophilic cellulolytic anaerobes from icelandic hot springs. Antonie van Leeuwenhoek 68:263-271.

Chen CC, Hwang JK, Yang JM (2006) (PS)2: protein structure prediction server. Nucleic Acids Res 34:W152-W157.

Crawford DL, McCoy E (1972) Cellulases of Thermomonospora fusca and Streptomyces thermodiastaticus. Appl Microbiol 24:150-152.

Dashtban M, Maki M, Leung KT et al. (2010) Cellulase activities in biomass conversion: measurement methods and comparison. Crit Rev Biotechnol 30:302-309.

Dosztanyi Z, Magyar C, Tusnády G et al. (2003) SCide: identification of stabilization centers in proteins. Bioinformatics 19:899-900.

Ferrer M, Golyshina O, Beloqui A et al. (2007) Mining enzymes from extreme environments. Curr Opin Microbiol 10:207214.

Hemmat J, Emtiazi G (2001) Isolation of Cellulomonas sp.From Silk worm's Gut and Evaluation of its Endoglucanase Activity. Iranian J Agric Sci 31:255-260.

Hreggvidsson GO, Kaiste E, Holst O et al. (1996) An extremely thermostable cellulase from the thermophilic eubacterium Rhodothermus marinus. Appl Environ Microbiol 62:30473049.

Karnaouri AC, Topakas E, Christakopoulos P (2014) Cloning, expression, and characterization of a thermostable GH7 endoglucanase from Myceliophthora thermophila capable of high-consistency enzymatic liquefaction. Appl Microbiol Biotechnol 1:231-242. 
Kuhad RC, Gupta R, Singh A (2011) Microbial cellulases and their industrial applications. Enzyme Res 2011:280696. doi: 10.4061/2011/280696. Epub 2011 Sep 7.

Li DC, Li AN, Papageorgiou AC (2011) Cellulases from thermophilic fungi: recent insights and biotechnological potential. Enzyme Res doi:10.4061/2011/308730.

Liang Y, Yesuf J, Schmitt S et al. (2009) Study of cellulases from a newly isolated thermophilic and cellulolytic Brevibacillus sp. strain JXL. J Ind Microbiol Biotechnol 36:961-970.

Mead DA, Lucas S, Copeland A et al. (2012) Complete genome sequence of Paenibacillus strain Y4. 12MC10, a novel Paenibacillus lautus strain isolated from Obsidian Hot Spring in Yellowstone National Park. Stand Genomic Sci 6:381-400.

Pal A, Khanum F (2011) Identification and optimization of critical medium components using statistical experimental designs for enhanced production of xylanase from Aspergillus flavus DFR-6. Food Technol. Biotechnol 49:228-236.

Pascon RC, Bergamo RF, Spinelli RX et al. (2011) Amylolytic microorganism from São Paulo zoo composting: isolation, identification, and amylase production. Enzyme Res. 2011;2011:679624. doi: 10.4061/2011/679624. Epub 2011 Aug 9.

Picart P, Diaz P, Pastor FI (2008) Stachybotrys atra BP-A produces alkali-resistant and thermostable cellulases. Antonie Van Leeuwenhoek 94:307-316.

Podosokorskaya OA, Merkel AY, Kolganova TV et al. (2011) Fervidobacterium riparium sp. nov., a thermophilic anaerobic cellulolytic bacterium isolated from a hot spring. Int $\mathrm{J}$ Syst Evol Microbiol 61:2697-2701.

Rastogi G, Bhalla A, Adhikari A et al. (2010) Characterization of thermostable cellulases produced by Bacillus and Geobacillus strains. Bioresour Technol 101:8798-8806.

Sadhu S, Saha P, Sen SK et al. (2013) Production, purification and characterization of a novel thermotolerant endoglucanase
(CMCase) from Bacillus strain isolated from cow dung. Springer Plus 2:1-10.

Sami AJ, Akhtar MW, Malik NN et al. (1988) Production of free and substrate-bound cellulases of Cellulomonas flavigena. Enzyme Microb Technol 10:626-631.

Sukumaran RK, Singhania RR, Pandey A (2005) Microbial cellulases-production, applications and challenges. J Sci Ind Res 64:832-844.

Susanti D, Johnson EF, Rodriguez JR et al. (2012) Complete Genome Sequence of Desulfurococcus fermentans, a Hyperthermophilic Cellulolytic Crenarchaeon Isolated from a Fresh water Hot Spring in Kamchatka, Russ. J Bacteriol 194:5703-5704.

Tamura K, Dudley J, Nei M et al. (2007) MEGA4: molecular evolutionary genetics analysis (MEGA) software version 4.0. Mol Biol Evol 24:1596-1599.

Teather RM, Wood PJ (1982) Use of Congo red-polysaccharide interactions in enumeration and characterization of cellulolytic bacteria from the bovine rumen. Appl Environ Microbiol 43:777-780.

Van Maris AJ, Abbott DA, Bellissimi E et al. (2006) Alcoholic fermentation of carbon sources in biomass hydrolysates by Saccharomyces cerevisiae: current status. Antonie Van Leeuwenhoek 90:391-418.

Wood TM, Bhat KM (1988) Methods for measuring cellulase activities. Methods Enzymol 160:87-112.

Zhang YQ, Schumann $\mathrm{P}$, Li WJ et al. (2005) Isoptericola halotolerans sp. nov., a novel actinobacterium isolated from saline soil from Qinghai Province, north-west China. Int J Syst Evol Microbiol 55:1867-1870.

\section{Associate Editor: Jorge Gonzalo Farias Avendano}

All the content of the journal, except where otherwise noted, is licensed under a Creative Commons License CC BY-NC. 